\title{
SISTEM INFORMASI GEOGRAFIS PENYEBARAN USAHA MIKRO KECIL MENENGAH (UMKM) DI KABUPATEN MAJALENGKA
}

\author{
Muhammad Darul Husni Santoso , Ikbal Jamaludin², Evi Dewi Sri Mulyani*3 \\ 1,2,3 Teknik Informatika, STMIK Tasikmalaya \\ Email: 1darul@stmik-tasikmalaya.ac.id, ${ }^{2}$ ikbal@stmik-tasikmalaya.ac.id, ${ }^{3}$ eviajadech@gmail.com \\ *Penulis Korespondensi
}

(Naskah masuk: 19 September 2019, diterima untuk diterbitkan: 07 Oktober 2020)

\begin{abstract}
Abstrak
Kabupaten Majalengka merupakan wilayah yang mengalami perkembangan pesat yang memiliki sumber daya alam yang beraneka ragam yang dapat diolah menjadi bentuk berbagai produk. Dengan berkembangnya Usaha Mikro Kecil Menengah (UMKM) di Kabupaten Majalengka dapat menggerakan perekonomian masyarakat, khususnya di sektor bawah, yaitu untuk usaha mikro kecil menengah. Pada saat ini, di Kabupaten Majalengka belum memiliki sistem yang mampu memberikan informasi yang ditampilkan secara spasial mengenai persebaran lokasi UMKM, dimana nantinya sistem ini bertujuan untuk memberikan informasi yang dapat dijadikan bahan pertimbangan yang tepat dalam menentukan kebijakan yang berkaitan dengan pertumbuhan Usaha Mikro Kecil Menengah (UMKM) di Kabupaten Majalengka, seperti pengadaan pelatihan usaha, pemberian modal usaha dan lain sebagainya. Maka dari itu untuk membantu mengawasi pertumbuhan UMKM tersebut, diperlukan adanya sebuah sistem yang berbasis geografis yang dapat memberikan informasi lokasi pertumbuhan UMKM secara spasial bagi Dinas terkait, yang direpresentasikan dengan sistem koordinat ditunjukan melalui penyimpanan titik longitude (long) dan latitude (lat) dalam database pada setiap lokasinya sebagai dasar pertimbangan dalam menentukan kebijakan Pemerintah di Kabupaten Majalengka. Pada penelitian ini, metode yang digunakan dalam pembangunan sistem ini menggunakan System Development Life Cycle $(S D L C)$, sistem ini akan dirancang dengan berbasis Web Geographic Information System (WebGIS) yang menggunakan fasilitas dari Google Maps dan sistem ini diuji dengan menggunakan metode blackbox. Dengan dibangunnya sistem ini, maka informasi mengenai titik lokasi serta data UMKM yang sesuai dengan kegiatan usahanya dapat ditampilkan. Hasil penelitian ini berupa sistem informasi geografis, dimana sistem ini dapat memberikan informasi kepada Dinas Koperasi dan UMKM di Kabupaten Majalengka mengenai informasi lokasi penyebaran UMKM secara spasial yang dapat membantu dalam pengelolaan dan pengawasan terhadap pertumbuhan usaha berdasarkan lokasi dan jenis UMKM tersebut.
\end{abstract}

Kata kunci: WebGIS, Sebaran UMKM, Google MapAPI

\section{GEOGRAPHIC INFORMATION SYSTEMS DISTRIBUTION OF MICRO, SMALL AND MEDIUM ENTERPRISE (MSMES) IN MAJALENGKA DISTRICT}

\begin{abstract}
Majalengka Regency is a region that is experiencing rapid development that has diverse natural resources that can be processed into various forms of products. With the development of Micro, Small and Medium Enterprises (MSMEs) in Majalengka Regency, it can move the community's economy, especially in the lower sector, namely for micro small and medium businesses. At present, Majalengka Regency does not yet have a system capable of providing information that is displayed spatially about the distribution of MSME locations, where later this system aims to provide information that can be used as appropriate consideration in determining policies relating to the growth of Micro, Small and Medium Enterprises (MSMEs) in Majalengka Regency, such as procurement of business training, provision of venture capital and so on. Therefore to help oversee the growth of MSMEs, a geographic based system is needed that can provide spatial information on MSME growth locations for the relevant Dinas, represented by a coordinate system shown through storing longitude and latitude points at each location as a basis for consideration in determining Government policy in Majalengka Regency. In this study, the method used in the construction of this system uses the System Development Life Cycle (SDLC), this system will be designed with a Web-based Geographic Information System (WebGIS) that uses facilities from Google Maps and the system is tested using the blackbox method. With the construction of this system, information about the location points as well as MSME data in accordance with their business activities can be
\end{abstract}


displayed. The results of this study are in the form of a geographic information system, in which this system can provide information to the Cooperative and MSME Service Offices in Majalengka Regency regarding spatial information on MSME distribution locations that can assist in the management and supervision of business growth based on the location and type of MSME.

\section{Keywords: WebGIS, MSMEs Distribution, Google MapAPI}

\section{PENDAHULUAN}

Secara faktor geografis, Kabupaten Majalengka berada di sebelah timur Provinsi Jawa Barat. Luas wilayah Kabupaten Majalengka adalah $1.204,24 \mathrm{Km}$. Dari luas wilayah tersebut dapay diartikan bahwa luas Kabupaten Majalengka sekitar $2,71 \%$ dari luas keseluruhan Propinsi Jawa Barat. Kabupaten Majalengka terbagi dalam 3 daerah yaitu : pegunungan, perbukitan dan daerah dataran rendah, sehingga dapat dikembangkan menjadi kota bisnis dan industri, dimana daerah ini berada pada dataran rendah yang sangat strategis sebagai wilayah penghubung 4 (empat) Kabupaten yakni Kabupaten Sumedang, Kabupaten Indramayu, Kabupaten Cirebon dan Kabupaten Kuningan yang memungkinkan tumbuh suburnya potensi sumber daya alam[1].

Kabupaten Majalengka merupakan wilayah yang mengalami perkembangan pesat yang memiliki sumber daya alam yang beraneka ragam yang dapat diolah menjadi bentuk berbagai produk. Ada 8 unit usaha yang masih aktif berproduksi, untuk itu dinas UMKM sangat memerlukan pertimbangan yang tepat dalam menentukan kebijakan yang berkaitan dengan pertumbuhan Usaha Mikro Kecil Menengah (UMKM) di Kabupaten Majalengka. Pada saat ini, di Kabupaten Majalengka belum memiliki sistem yang mampu memberikan informasi yang ditampilkan secara spasial mengenai persebaran lokasi UMKM, dimana nantinya sistem ini bertujuan untuk memberikan informasi yang dapat dijadikan bahan pertimbangan yang tepat dalam menentukan kebijakan yang berkaitan dengan pertumbuhan Usaha Mikro Kecil Menengah (UMKM) di Kabupaten Majalengka, seperti pengadaan pelatihan usaha, pemberian modal usaha dan lain sebagainya, maka dari itu diperlukannya sebuah sistem yang mampu memberikan informasi secara tepat dan akurat mengenai lokasi pertumbuhan UMKM secara spasial ke Dinas terkait sebagai dasar pertimbangan dalam menentukan kebijakan Pemerintah yang berkaitan dengan UMKM di Kabupaten Majalengka.

Sistem yang dibangun pada penelitian sebelumnya dapat menghasilkan informasi lokasi UMKM berbasis Geografis, maka informasi yang dihasilkan dan proses monitoring akan menjadi lebih mudah dilakukan untuk semua jenis UMKM yang berada di Kabupaten Kudus[2]. Selain itu dalam penelitian lainnya dengan sistem yang berbasis geografis mampu membantu Dinas setempat dalam pengelolaan dan pengawasan terhadap UMKM dari hasil informasi mengenai sebaran UMKM[3].
Sistem yang akan dirancang ini smerupakan ebuah sistem yang berbasis Web Geographic Information System (WebGIS) yang memanfaatkan fasilitas dari Google Map, dimana fasilitas ini dapat didapatkan secara gratis atau tidak berbayar. Google Maps merupakan sebuah jasa peta globe virtual yang gratis dan dapat diakses online dimana perusahaan Google, Inc sebagai penyedianya, untuk mengakses fasilitas tersebut dapat melalui link http://maps.google.com/. Pada prinsipnya, Google Map dapat menampilkan layout visual berbentuk peta, tampilan gambar dari satelit dan tampilan jalan di seluruh dunia, serta menawarkan perencana rute (direction) dan pencarian lokasi[4]. Sistem Informasi Geografis (SIG) yang berbasis $W e b$ (WebGIS) adalah sebuah aplikasi yang didalamnya memanfaatkan jaringan internet sebagai media komunikasi[5]. Sistem yang dibangun pada penelitian sebelumnya menggunakan fasilitas WebGis, yang mampu memberikan output berupa informasi titik lokasi penyebaran penyakit di sebuah wilayah tertentu[6].

Sistem ini dirancang agar dapat memberikan informasi mengenai sebaran titik lokasi setiap UMKM yang dapat ditampilkan sesuai dengan kategori usaha, lokasi per kecamatan, serta menampilkan data usaha setiap UMKM dengan detail, yaitu nama, kategori, kegiatan usaha, jenis, keterangan, dan alamat, serta dapat memberikan informasi kepada Dinas Koperasi dan UMKM di Kabupaten Majalengka mengenai lokasi penyebaran UMKM yang dapat membantu dalam pengelolaan dan pengawasan terhadap pertumbuhan usaha berdasarkan lokasi dan jenis UMKM tersebut

\section{METODE PENELITIAN}

\subsection{Kerangka penelitian}

Gambar 1 menggambarkan mengenai kerangka penelitian yang akan dilakukakn dari mulai tahapan perencanaan, tahapan analisis, tahapan desain dan tahapan implementasi.

\subsection{Metode Pengembangan Sistem}

Dalam penelitian ini, metode yang digunakan untuk pengembangan sistemnya menggunakan metode System Development Life Cycle (SDLC) dengan pendekatan waterfall yang merupakan model pengembangan sistem informasi yang sistematik dan sekuensial [7]. Pada penelitian sebelumnya proses perancangan sistem informasi geografis yang dibangun, mampu memberikan output berbentuk grafik dan informasi lainnya berdasarkan daerah tertentu [8]. Metode ini mampu 
memberikan pendekatan secara sistematik dan sekuensial, dimulai fase perencanaan kemudian dilakukannya analisis pada sistem, dilanjutkan dengan desain sistem, dan yang terakhir adalah implementasi sistem (pengkodean, pengujian dan pemeliharaan).

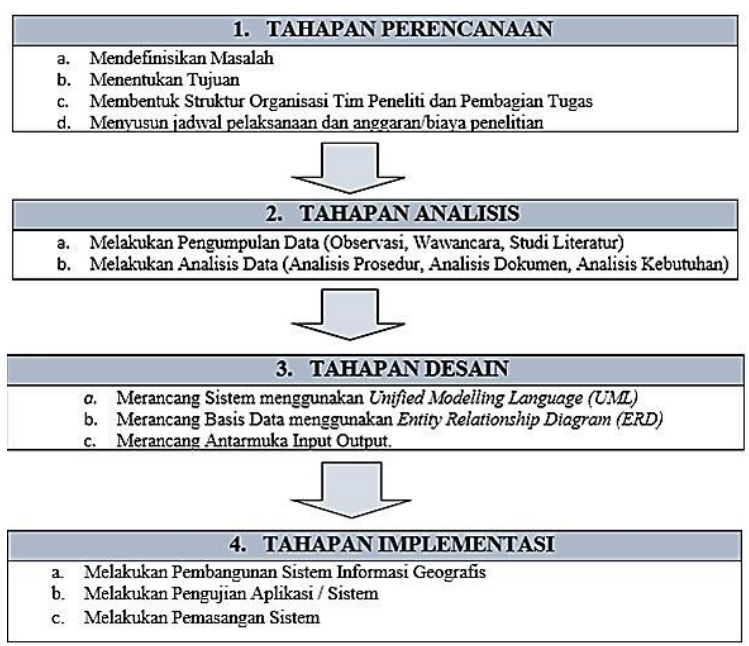

Gambar 1. Kerangka Penelitian

Untuk merancang Sistem informasi geografis ini, Penulis menggunakan Unified Modeling Language (UML), agar memudahkan dalam proses implementasi pada sistemnya.

\section{HASIL DAN PEMBAHASAN}

\subsection{Perencanaan}

Pada saat ini, di Kabupaten Majalengka belum memiliki sistem yang mampu memberikan informasi yang ditampilkan secara spasial mengenai persebaran lokasi UMKM, sehingga untuk dapat menghasilkan informasi tersebut perlunya dibangun sebuah sistem yang bertujuan untuk memberikan informasi yang dapat dijadikan bahan pertimbangan yang tepat dalam menentukan kebijakan yang berkaitan dengan pertumbuhan Usaha Mikro Kecil Menengah (UMKM) di Kabupaten Majalengka, seperti pengadaan pelatihan usaha, pemberian modal usaha dan lain sebagainya.

\subsection{Analisis Sistem}

Data yang dikumpulkan Penulis dalam membangun sistem ini, baik data primer maupu sekunder dalam menyelesaikan penelitian ini. Salah satunya yaitu data UMKM yang Penulis dapatkan dari portal http://data.majalengkakab.go.id/dataset/ ?org=dinas-koperasi-usaha-mikro-kecil-danmenengah yaitu data jumlah UMKM bidang Agrobisnis, bidang fashion, bidang kuliner, bidang otomotif dan lainnya di Kabupaten Majalengka Tahun 2017-2018. Data penelitian diatas didapatkan dari sumber lainnya, yaitu diantara data tersebut dari hasil sensus, data dalam sebuah artikel dan data hasil interview dengan sumber-sumber yang memiliki pengetahuan dan informasi tentang UMKM di Kabupaten Majalengka.

\subsection{Perancangan Sistem}

Dibawah ini akan dijelaskan mengenai pembahasan dan perancangan sistem informasi geografis UMKM di Kabupaten Majalengka.

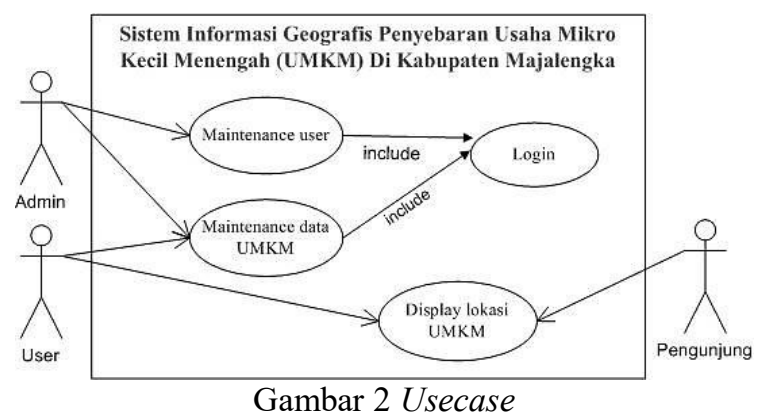

Gambar 2 diatas dapat menjelaskan interaksi yang terjadi antara aktor yaitu admin, user dan pengunjung, dimana ketiga aktor tersebut memiliki keterkaitan.

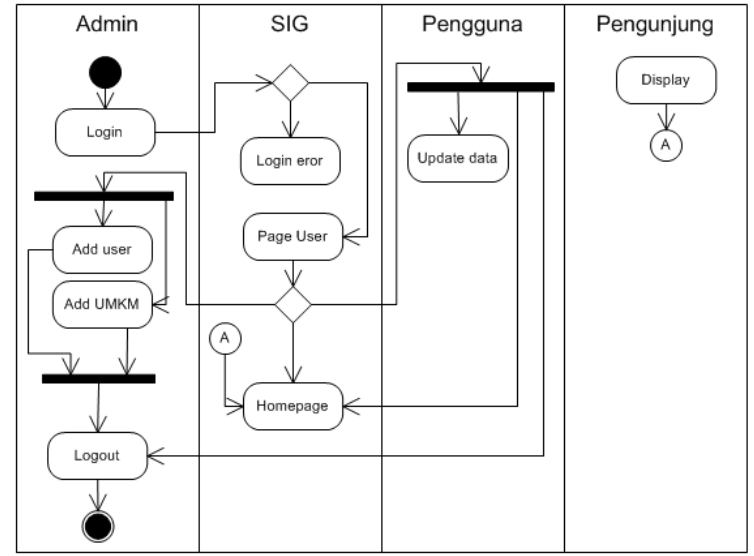

Gambar 3 Activity Diagram

Gambar 3 diatas menjelaskan mengenai aktifitas yang terjadi dalam sistem informasi geografis UMKM di Kabupaten Majalengka.

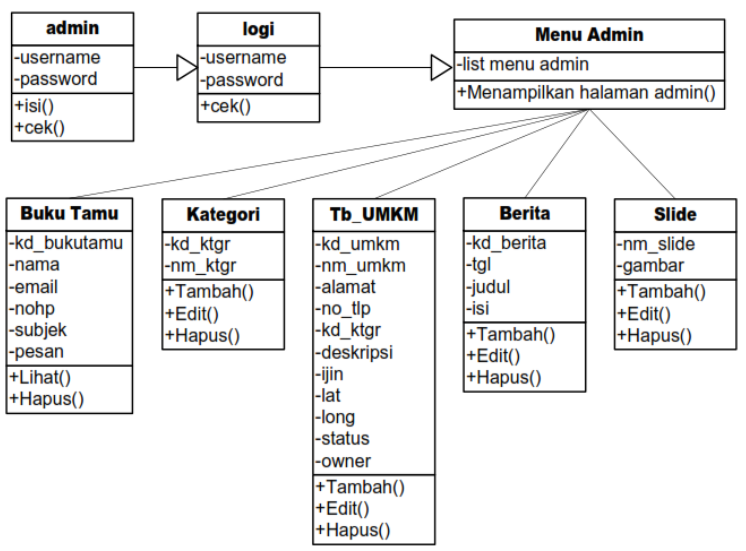

Gambar 4 Class Diagram 
Gambar 4 diatas menjelaskan mengenai class diagram yang merupakan aktivitas inti yang sangat mempengaruhi arsitektur aplikasi yang dirancang untuk melanjutkan ke tahap pengkodean dan perancangan database dalam pembangunan sistem informasi geografis UMKM di Kabupaten Majalengka.

\subsection{Implementasi Sistem}

Berikut adalah tampilan input dan output Sistem Informasi Geografis UMKM di Kabupaten Majalengka :
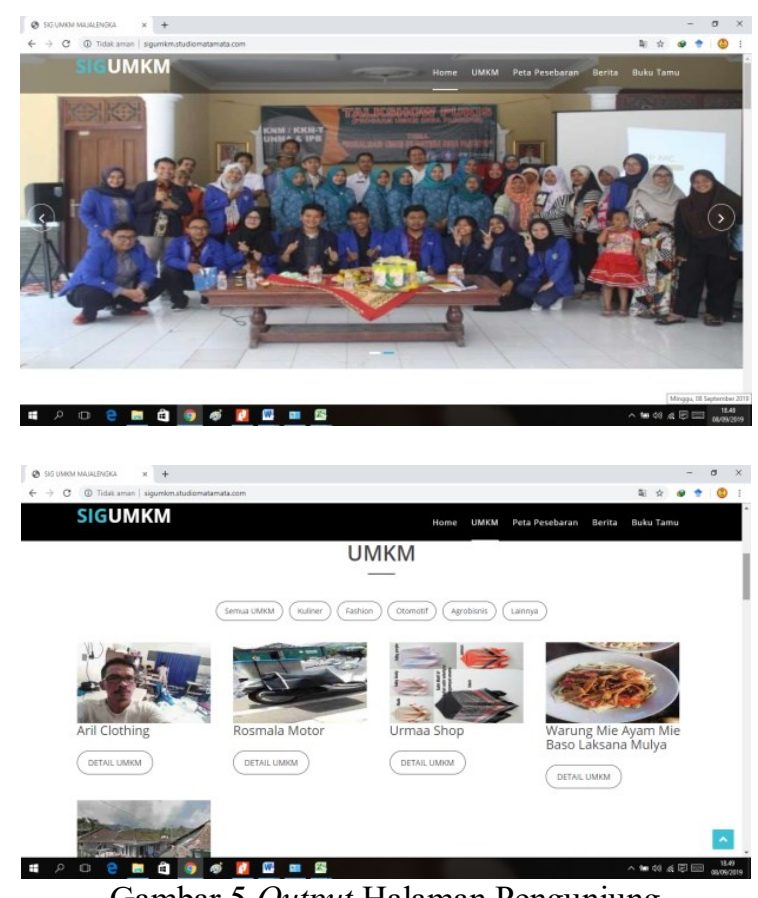

Gambar 5 Output Halaman Pengunjung

Gambar 5 diatas merupakan halaman pengunjung, pada halaman tersebut akan ditampilkan data UMKM dan jika di klik detail UMKM, akan ditampilkan data Informasi UMKM seperti Gambar 8.

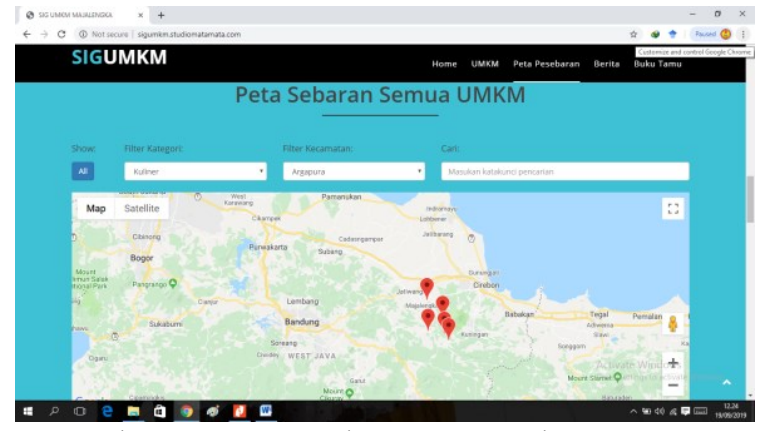

Gambar 6 Output Halaman Peta Sebaran Semua UMKM

Gambar 6 diatas adalah halaman yang menampilkan peta sebaran semua UMKM di Kabupaten Majalengka. Tampilan diatas memberikan informasi lokasi serta detail data
UMKM jika titik tersebut di klik (Gambar 8), dan tampilan tersebut dapat diakses oleh Dinas yang bertujuan sebagai dasar pertimbangan dalam menentukan kebijakan Pemerintah di Kabupaten Majalengka yang berkaitan dengan penyebaran UMKM. Adapun bagi pelaku UMKM hal ini dapat menjadi bahan acuan dalam membantu strategi marketing dalam mengembangkan usahanya dengan mengetahui lokasi usaha kompetitor ataupun jenis usaha yang mampu mendukung usahanya sendiri. Adapun bagi pengunjung, sistem dapat membantu menemukan jenis usaha-usaha beserta lokasi UMKM yang sedang diperlukan informasinya.

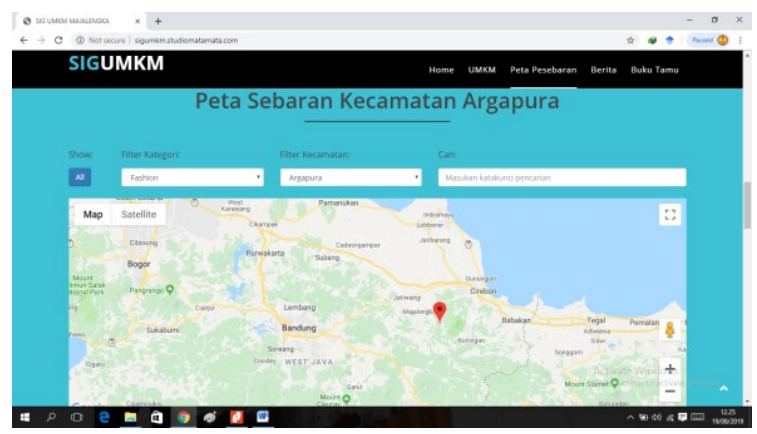

Gambar 7 Output Halaman Peta Sebaran UMKM Per Kecamatan dan per Kategori

Peta sebaran UMKM pun dapat ditampilkan berdasarkan kecamatan yang ada di Kabupaten Majalengka, pengguna dapat menggunakan fasilitas filter Kecamatan yang sudah disediakan pada halaman tersebut yang ditampilkan pada gambar 7 diatas, dengan mengklik panah combo box hingga tampil list kecamatan dan klik salah satu kecamatan yang dikehendaki.

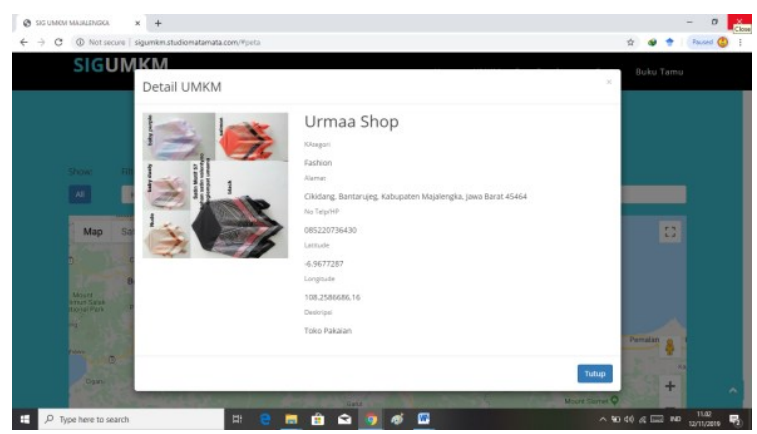

Gambar 8 Output Halaman Detail Informasi UMKM

Pada gambar 8 ditampilkan informasi detail mengenai UMKM, yang terdiri dari nama, alamat, beserta informasi lainnya yang bertujuan untuk memberikan informasi lebih lengkap kepada pengunjung.

Pada gambar 9 ditampilkan halaman login untuk admin selaku administrator sistem, dimana seorang admin memiliki akses penuh untuk mengelola sistem, mulai dari menambah, merubah serta menghapus data yang ada dalam sistem dalam hal ini adalah pegawai Dinas yang diberi tugas untuk mengelola data UMKM yang berperan juga sebagai 
back-end system. Halaman login ini tidak diperuntukan bagi pengunjung maupun pelaku UMKM, sehingga ketika ada perubahan data, pemilik UMKM dapat mengajukan perubahan data ke Dinas.

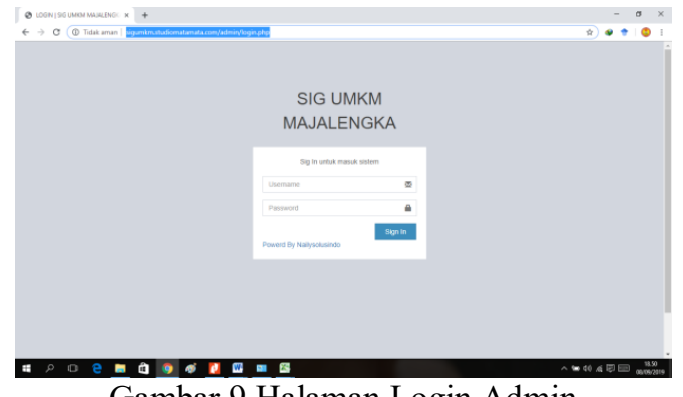

Gambar 9 Halaman Login Admin

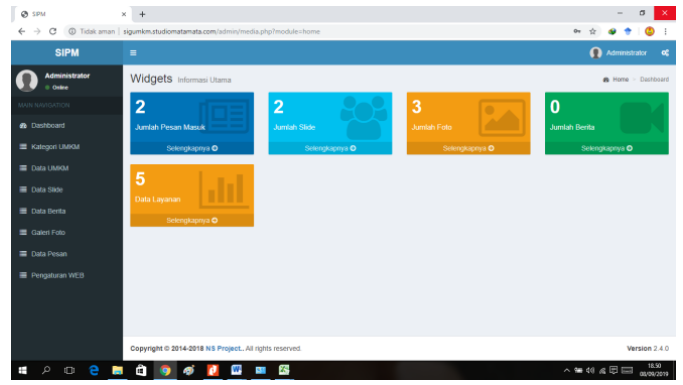

Gambar 10 Halaman Admin

Gambar 10 diatas merupakan halaman administrator, pada halaman tersebut admin dapat mengakses untuk mengelola data pengguna, data kategori UMKM, data UMKM, data berita, data foto, data slide dan data pesan.
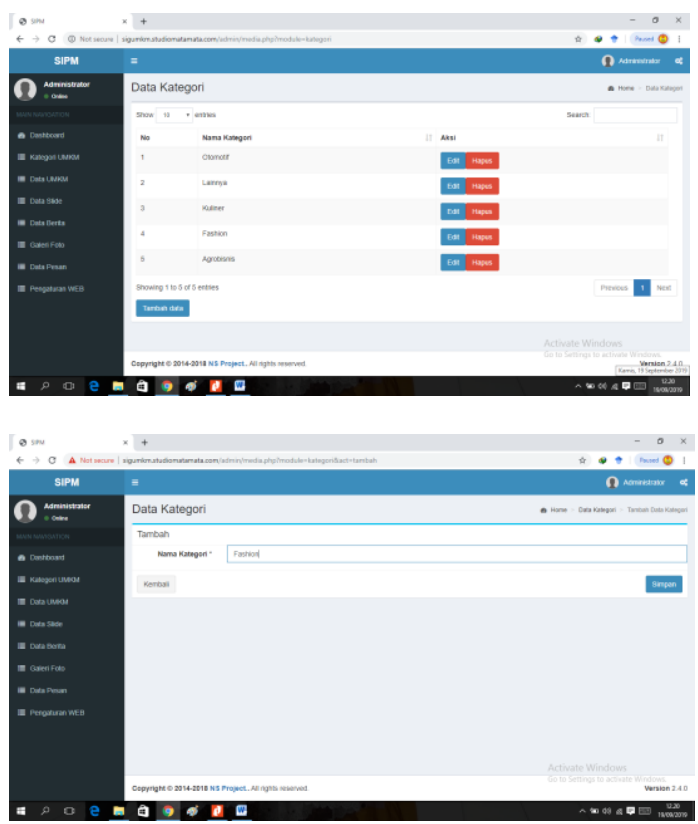

Gambar 11 Halaman Input Data Kategori UMKM
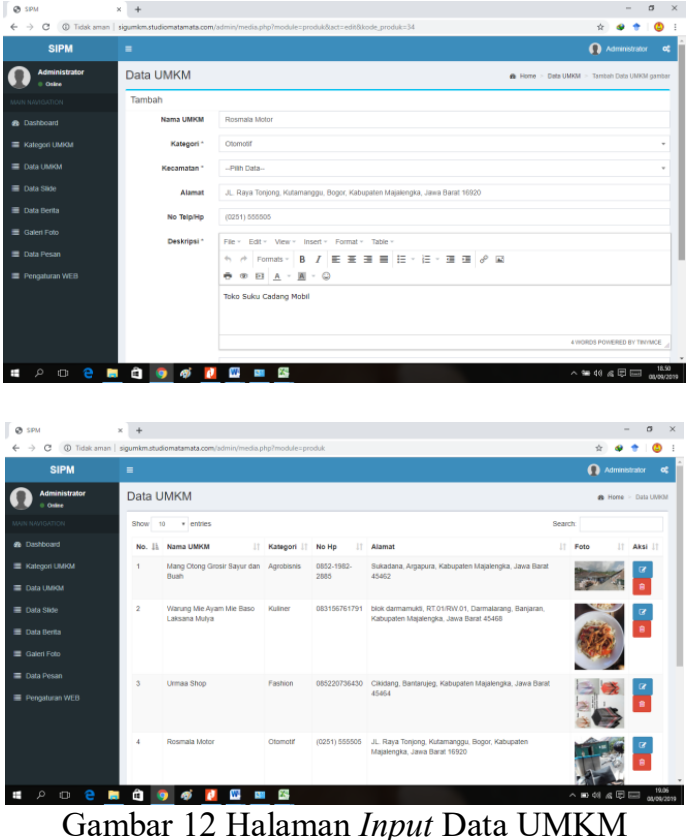

Pada Gambar 11 dan Gambar 12 merupakan fungsi yang dapat dilakukan oleh admin untuk maintenance data melalui fitur layanan admin.

Gambar 11 adalah layout untuk mengelola data kategori UMKM, form tersebut disediakan untuk memasukan, merubah dan menghapus data kategori UMKM dan untuk mengelola data UMKM disediakan halaman input UMKM pada gambar 12 .

Untuk pengujian terhadap software dilakukan dengan metode blackbox. Dengan metode ini, fungsionalitas sistem akan diuji, pengujian ini dilakukan dengan menjalankan fungsi-fungsi pada sistem yang dibangun untuk mengevaluasi semua fasilitas apakah proses verifikasi dan validasi data dapat dijalankan dengan baik atau tidak. Berikut hasil pengujian yang dilakukan pada Sistem Informasi Geografis UMKM di Kabupaten Majalengka seperti pada Tabel 1

Tabel 1. Pengujian Input UMKM

Pengujian Fungsi Input UMKM

\begin{tabular}{|c|c|c|c|}
\hline Data Masukan & $\begin{array}{c}\text { Yang } \\
\text { Diharapkan }\end{array}$ & $\begin{array}{c}\text { Pengamat } \\
\text { an }\end{array}$ & Kesimpulan \\
\hline $\begin{array}{l}\text { Input data pada } \\
\text { semua isian } \\
\text { UMKM }\end{array}$ & $\begin{array}{l}\text { Data UMKM } \\
\text { dapat tersimpan } \\
\text { setelah klik } \\
\text { tombol simpan }\end{array}$ & $\begin{array}{l}\text { Form input } \\
\text { data } \\
\text { UMKM }\end{array}$ & $\begin{array}{l}{[\sqrt{ }] \text { Diterima }} \\
{[\text { ] Ditolak }}\end{array}$ \\
\hline $\begin{array}{l}\text { Mengosongkan } \\
\text { data pada isian } \\
\text { data UMKM } \\
\text { yang bertanda } \\
\text { bintang }(*)\end{array}$ & $\begin{array}{l}\text { Maaf data tidak } \\
\text { dapat tersimpan } \\
\text { / tidak bisa } \\
\text { masuk ke } \\
\text { halaman } \\
\text { selanjutnya }\end{array}$ & $\begin{array}{l}\text { Maaf ada } \\
\text { data } \\
\text { kosong }\end{array}$ & $\begin{array}{l}{[\text { ] Diterima }} \\
{[\sqrt{ }] \text { Ditolak }}\end{array}$ \\
\hline $\begin{array}{l}\text { Memilih nama, } \\
\text { Kecamatan, } \\
\text { Kategori, } \\
\text { alamat, notlp, } \\
\text { deskripsi, lat, } \\
\text { lng, foto } \\
\text { kemudian }\end{array}$ & $\begin{array}{l}\text { Tersimpan data } \\
\text { UMKM }\end{array}$ & $\begin{array}{l}\text { Menyimpa } \\
\text { n data } \\
\text { UMKM }\end{array}$ & $\begin{array}{l}{[\sqrt{ }] \text { Diterima }} \\
{[\text { ] Ditoak }}\end{array}$ \\
\hline
\end{tabular}




\begin{tabular}{|c|c|c|c|}
\hline \multicolumn{4}{|c|}{ Pengujian Fungsi Input UMKM } \\
\hline simpan & & & \\
\hline $\begin{array}{l}\text { Memasukan } \\
\text { latitude dan } \\
\text { longitude tapi } \\
\text { tipe tidak sesuai }\end{array}$ & $\begin{array}{l}\text { Maka akan } \\
\text { tampil kembali } \\
\text { form UMKM }\end{array}$ & $\begin{array}{l}\text { Kembali } \\
\text { ke form } \\
\text { UMKM }\end{array}$ & $\begin{array}{l}{[\sqrt{ }] \text { Diterima }} \\
{[\text { ] Ditolak }}\end{array}$ \\
\hline
\end{tabular}

Dari hasil pengujian black box terhadap validasi dan fungsional pada aplikasi yang dibangun dapat disimpulkan bahwa setiap form memberikan respon yang sesuai dengan yang diharapkan.

\section{KESIMPULAN}

Kesimpulan dari penelitian yang telah dilakukan ini, bahwasannya Sistem Informasi Geografis yang dibangun sudah memenuhi kebutuhan pengguna dengan memiliki fitur-fitur yang mampu memberikan informasi secara geografis yang dilengkapi dengan atribut-atribut, sehingga sistem dapat diujicobakan secara nyata dilapangan. Dengan pengujian secara nyata inilah, akan menimbulkan ide pemikiran untuk penelitian selanjutnya bagi pengembangan sistem, khususnya mengenai kebermanfaatan (usability) yang dimiliki oleh sistem tersebut yang dapat diterima oleh Dinas Koperasi dan UMKM di Kabupaten Majalengka serta UMKM sebagai pengguna

\section{DAFTAR PUSTAKA}

ABDULLAH, B. A. 2018. Sistem Informasi Geografis Sebaran UMKM Di Kota Cimahi. Seminar Nasional Teknologi Informasi dan Multimedia, pp. 1.7-7-1.712.

ANGGRAENI, A. D. \& BUDISUSANTO, Y. 2016. Pembagunan Sistem Informasi Geografis Berbasis Web Untuk Pemetaan Industri Kreatif Berbasis Budaya Di Kota Surakarta. Jurnal Teknik ITS, 5(2). doi: 10.12962/j23373539.v5i2.17200.

Diskominfo. 2019. Profil Majalengka. Available at: https://majalengkakab.go.id/profilmajalengka- $2 /$.

PRESSMAN, R. . 2002. Rekayasa Perangkat Lunak: Pendekatan Praktisi(Buku Dua). 2nd edn. Yogyakarta: Penerbit Andi.

RINDO, A. \& RIASTI, B. K. 2011. Pembangunan Sistem Informasi Geografis Usaha Mikro Kecil. Journal Speed (Sentra Penelitian Engineering dan Edukasi), 3(2), pp. 27-33.

SASMITO, G. W. 2017. Penerapan Metode Waterfall Pada Desain Sistem Informasi Geografis Industri Kabupaten Tegal. Jurnal Informatika:Jurnal Pengembangan IT (JPIT), 2(1), pp. 6-12.

SRI MULYANI, E. D., dkk. 2018. Sistem Pakar Diagnosa Penyebaran Vektor Penyakit Dari Binatang Berbasis Webgis Di Wilayah Kota Tasikmalaya. CSRID (Computer Science Research and Its Development Journal),
9(3), $\quad$ p. $\quad 125 . \quad$ doi:

10.22303/csrid.9.3.2017.125-132.

WIJAYA, H. O. L. 2017. Perancangan Aplikasi Pemetaan Lokasi Usaha Kecil Menengah (UKM) Di Kota Lubuklinggau Berbasis Goegraphic Information System (GIS) Dan Location Based Service (LBS). Jatisi, Vol. 3 No. 2 Maret 2017, 3(2), pp. 85-93. 